\title{
PERANCANGAN SISTEM MANAJEMEN ASET BERBASIS ANDROID MENGGUNAKAN METODE SDLC STUDY KASUS BAU UNIVERSITAS YUDHARTA PASURUAN
}

\author{
Izzul Kholis ${ }^{1}$, Walidini Syaihul Huda ${ }^{2}$ \\ Universitas Yudharta Pasuruan ${ }^{1}$, Universitas Bina Nusantara ${ }^{2}$ \\ Jl. Pondok Pesantren Ngalah No.16 Sengonagung Purwosari Pasuruan \\ e-mail: kholisizzul@gmail.com
}

\begin{abstract}
Abstrak
Penelitian ini bertujuan untuk: (1) mengembangkan Sistem Manajemen Aset berbasis Android di Universitas Yudharta Pasuruan untuk memudahkan pengelolaan aset. (2) menjamin kualitas perangkat lunak agar memenuhi standar kualitas perangkat lunak ISO 25010. Jenis penelitian yang digunakan Research \& Development $(R \& D)$, dengan model pengembangan Model Waterfall yang terdiri dari lima tahap yaitu Requirement Analysis and Definition, System and Software Design, Implementation and Unit Testing, Integration and System Testing dan Operation and Maintenance. Hasil penelitian ini adalah: (1) Sistem informasi Manajemen Aset Berbasi Android untuk mempermudah pengelolaan aset di kampus. (2) hasil pengujian menunjukkan bahwa sistem ini telah sesuai dengan standard ISO 25010 pada karakteristik functional suitability sebesar 1, performance efficiency sebesar, dan memenuhi syarat karakteristik maintainability.
\end{abstract}

\section{Kata kunci : Sistem Manajemen Aset berbasis Android, Waterfall Model,Standar ISO 25010}

\section{Pendahuluan}

Universitas yudharta pasuruan merupakan universitas yang berada di lingkungan pondok pesantren ngalah dan merupakan salah satu kampus ternama di kabupaten pasuruan. Universitas yudharta pasuruan berdiri pada tahun 2001 yang saat ini sudah memiliki 16 jurusan dalam 5 fakultas termasuk salah satunya ialah teknik informatika, dengan usia kampus yang masih sangat muda ini universitas yudharta pasuruan sudah mampu bersaing dengan kampus lainnya. Universitas yudharta pasuruan memiliki elemen-elemen penting didalamnya termasuk salah satunya ialah BAU (Badan Administrasi Umum). BAU merupakan bagian yang mengelola semua administrasi umum yang dibutuhkan termasuk mengelola informasi aset dan inventaris dan juga mengelola sarana dan prasarana yang dibutuhkan untuk proses pengajaran.

Informasi merupakan sesuatu yang menunjukan hasil pengelolahan data yang di organisasi yang berguna bagi orang yang menerimanya.Teknologi informasi saat ini memang sudah banyak digunakan oleh setiap instansi ataupun perusahaan, tentang mengolah data informasi yang ada kedalam sebuah sistem yang lebih efektif, efisien dan menarik. Metode yang banyak digunakan dalam perancangan sistem informasi ialah metode SDLC (System Development Life Cycle). Metode SDLC adalah proses pembuatan dan pengolahan sistem serta model dan metodologi yang digunakan untuk mengembangkan suatu sistem, SDLC juga merupakan pola yang diambil untuk untuk mengembangkan sistem perangkat lunak yang terdiri dari beberapa tahapan tahapan dan metodologi kerangka kerja untuk perencanaa dan pengendalian sistem.

Seiring dengan berjalannya waktu,masih banyak masalah yang terjadi pada pengelolaan aset yang dimiliki, mulai dari pencatatan aset yang dilakukan secara manual sehingga menyebabkan penelusuran aset akan menjadi lebih sulit, inventarisasi yang belum jelas, belum adanya sistem yang terintegrasi dapat menyebabkan pembuatan laporan aset menjadi lebih sulit, selain itu dari sisi biaya penggunaan kertas dan tinta menyebabkan biaya yang lebih tinggi. Oleh karena itu diperlukan sebuah Sistem Informasi Manajemen Aset yang dapat mengelola seluruh aset yang ada agar lebih mudah untuk dipantau dikelola dan ditelusuri. Kebutuhan informasi mengenai data dan informasi suatu aset sangatlah penting guna untuk pengambilan keputusan yang tepat agar aset yang dikelola berfungsi secara efektif dan efisien.. Dimana tiap aset memiliki umur dan cara perawatan yang berbeda-beda. Pada saat ini, kurangnya media untuk mengelola seluruh aset yang ada agar lebih mudah untuk dipantau, dikelola dan ditelusuri secara efektif dan efesien 
Beberapa penelitian tentang perancangan sistem manajemen asset pernah dilakukan oleh beberapa peneliti, seperti yang telah dilakukan oleh (Nastiti \& Sunyoto, 2012) dalam penelitian ini, peneliti melakukan perancangan sistem manajemen asset pribadi berbasis android. Hasil penelitian ini menunjukkan bahwa perancangan aplikasi berbasis android ini menjadi solusi bagi masyarakat untuk meningkatkan efisiensi dan efektifitas pendataan dan pengelolaan manajemen aset pribadi mereka.

Penelitian selanjutnya dilakukan oleh (Hamzah \& Purwati, 2018) dalam penelitian ini, peneliti menggunakan metode near field communication pada studi kasus STIE Pelita Indonesia. Hasil penelitian ini menunjukkan bahwa perencanaan dan pemodelan sistem pelacakan inventory memudahkan dalam pengidentifikasian informasi setiap data inventaris dan memudahkan user dalam pencapaian informasi yang lebih efektif dan efisien.

Berikutnya penelitian dilakukan oleh (Suputra, Yota, Aryanto, \& Kertiasih, 2016) dalam penelitian ini, peneliti menggunakan metode geotangging. Hasil dari penelitian ini sistem inventaris mampu mengelola dan memanipulasi data inventaris dengan memanfaatkan 2D-Barcode (QR-Code) untuk mempermudah pencarian data melalui jaringan internet sehingga dapat diakses secara luas dengan perangkat di stasiun(dock-station) maupun perangkat bergerak (mobile).

Penelitian juga pernah dilakukan oleh Benben Bagus Prasetyo abdi DKK (Teknologi, Universitas, dan Malang, 2018) dalam penelitiannya metode yang digunakan ialah metode SDLC dengan model Waterfall. Hasil dari penelitian ini menunjukkan bahwa perancangan dan implementasi perancangan yang berupa aplikasi inventaris berbasis web berperan penting dalam pengelolaan dan pencatatan inventaris pada fakultas Teknologi Informasi Universitas Merdeka Malang, dengan adanya aplikasi ini inventarisasi semakin efektif dan efisien.

\section{Metode Penelitian}

Untuk memberikan panduan dalam penyusunan penelitian ini, maka perlu adanya susunan kerangka kerja (frame work) yang jelas tahapan-tahapannya. Kerangka kerja ini merupakan langkahlangkah yang akan dilakukan dalam penyelesaian masalah yang akan dibahas. Adapun kerangka kerja penelitian yang digunakan adalah sebagai berikut:

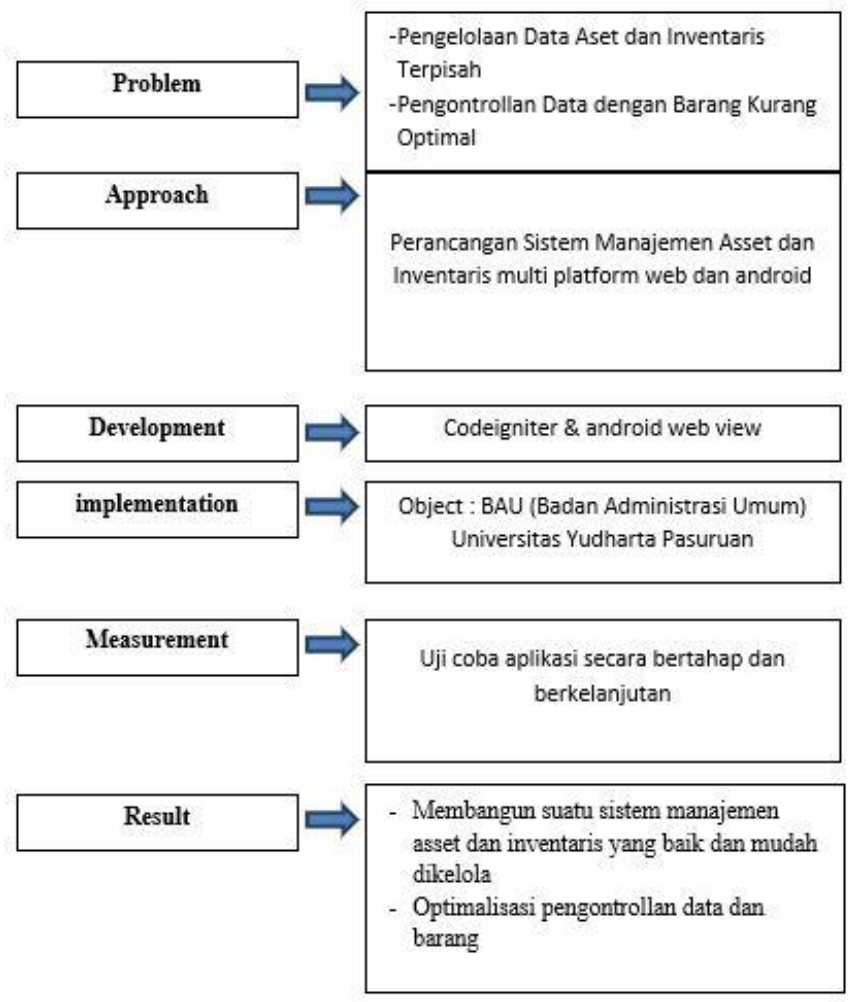

Gambar 1. Kerangka Konsep 


\section{Hasil dan Analisis}

a. Analisis Perancangan

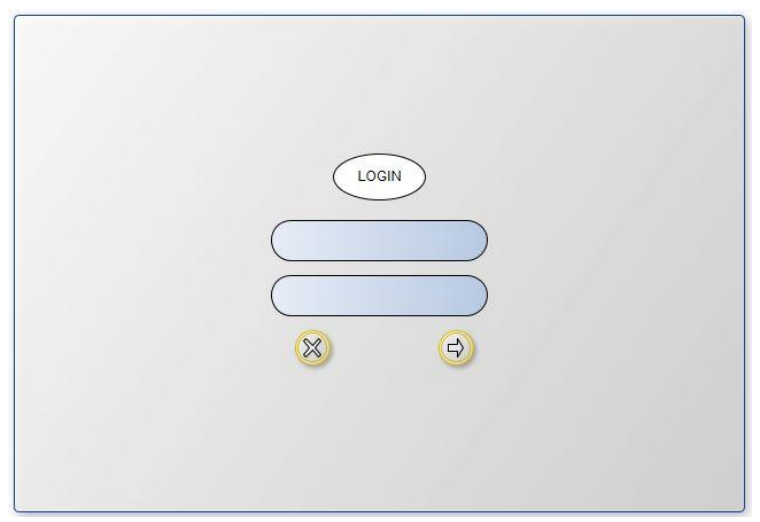

Gambar 2. Desain User Interface

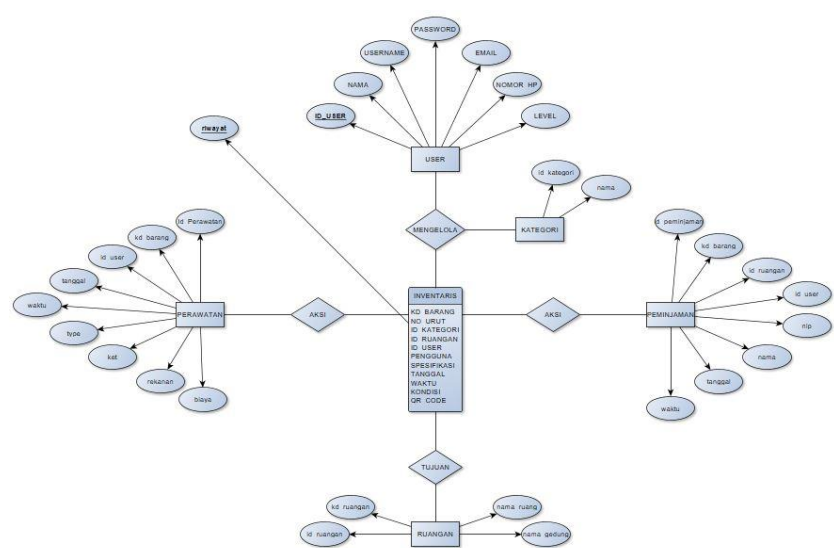

Gambar 3. Desain ERD

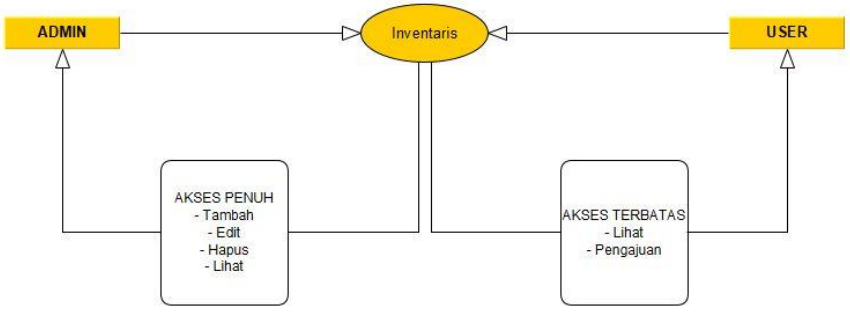

Gambar 4. DFF Level 0

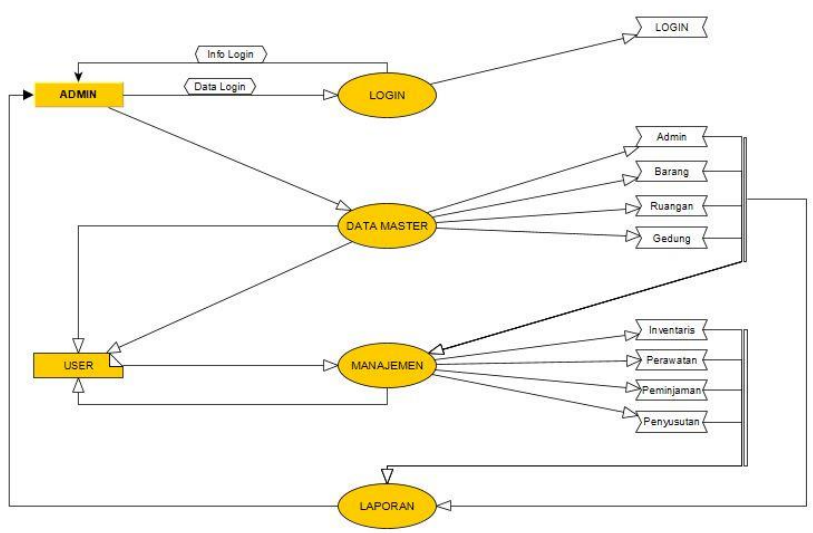




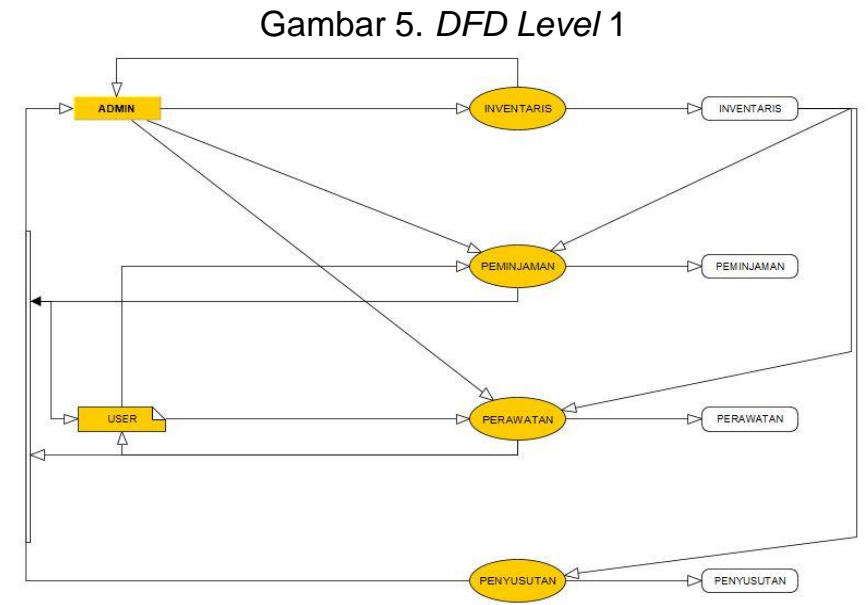

Gambar 6. DFD Level 2

Pemodelan perangkat lunak menggunakan notasi use case diagram dari UML (Unified Modeling Language). Diagram use case menjelaskan interaksi-interaksi yang terjadi antara perangkat lunak dengan lingkungannya. Diagram ini memberikan gambaran bagaimana instruksi-instruksi dari pengguna untuk melakukan suatu pekerjaan dilakukan oleh perangkat lunak melalui proses-proses yang ada di dalamnya. Mulai dari masukan yang diberikan yang kemudian diproses menghasilkan suatu keluaran yang diinginkan oleh pengguna.

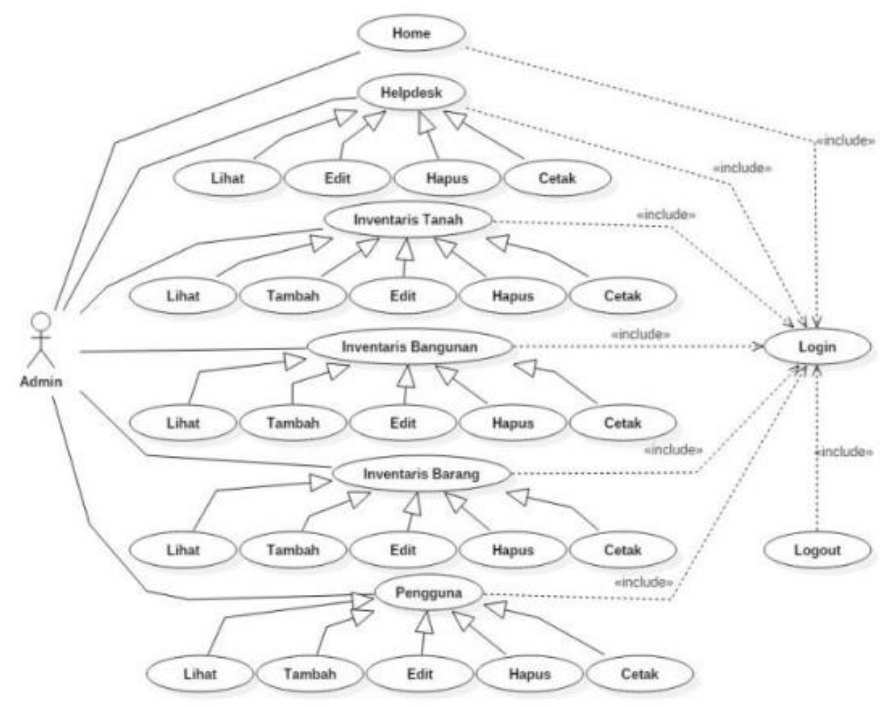

Gambar 7. Usecase Diagram

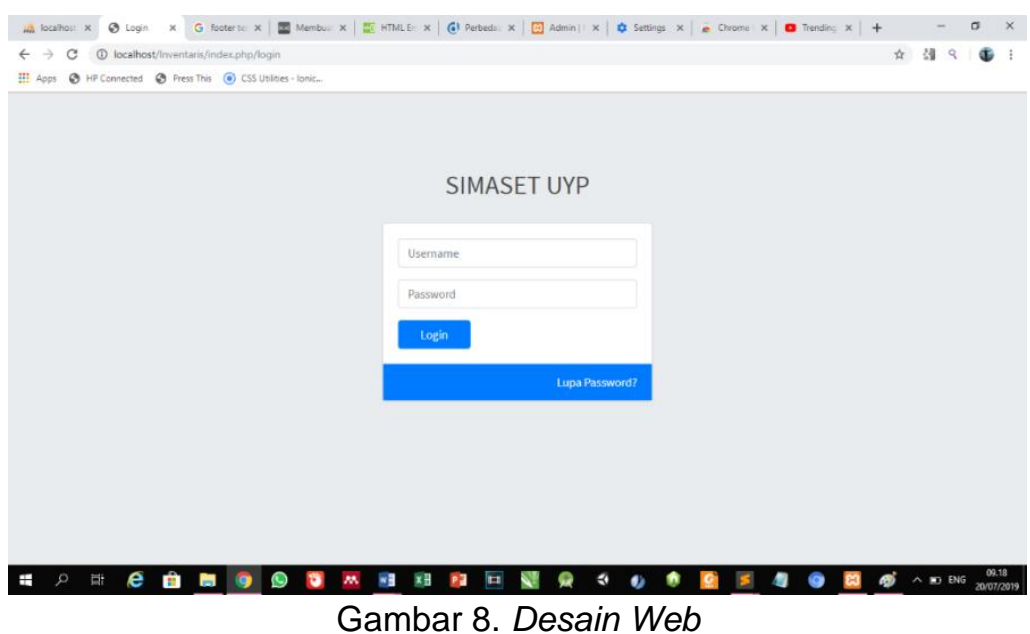




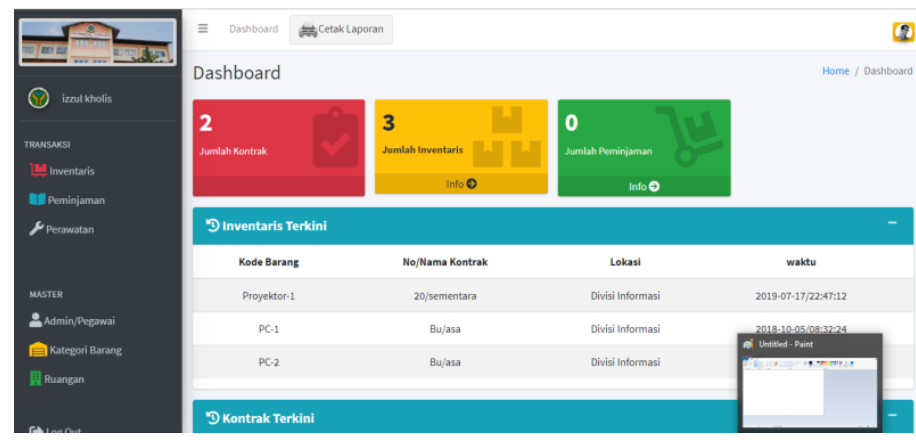

Gambar 9. Desain Web

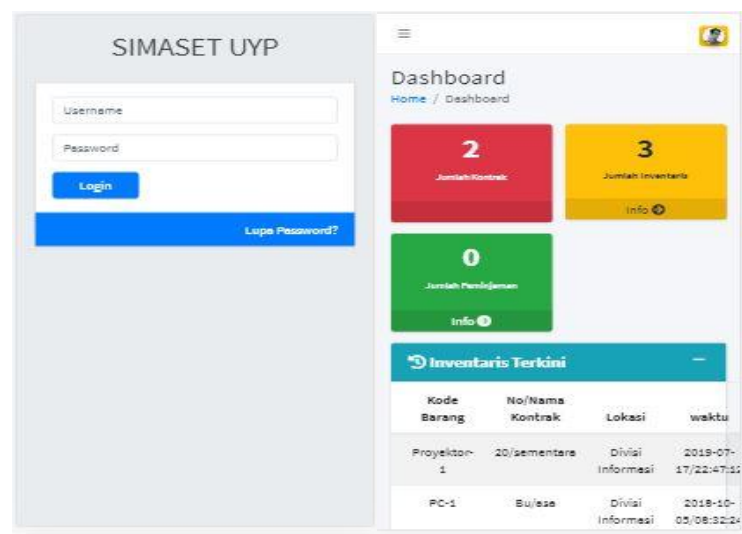

Gambar 10. Desain Android

b. Hasil Instrument Penelitian Standard ISO 25010

1. Instrument Suitability

Berdasarkan hasil pengujian instrumen penelitian functional suitability yang diujikan kepada para ahli media didapatkan tingkat keberhasilan mencapai $100 \%$. Pengujian sub karakeristik functional completeness, functional correctness, dan functional appropriateness menunjukkan nilai $x=1$ sehingga dapat disimpulkan bahwa Sistem Informasi inventaris barang ini telah memenuhi aspek functional suitability.

2. Instrument Usability

Berdasarkan hasil pengujian instrumen penelitian usability yang diujikan kepada pengguna sistem, dalam hal ini guru, didapatkan hasil penghitungan skor SUS 72. Skor SUS di atas 68 merupakan skor di atas rata-rata, sedangkan skor di bawah 68 dianggap di bawah rata-rata. Kualitas usability dianggap baik jika skor SUS di atas 68 . Sehingga, dapat disimpulkan dengan skor SUS 72 bahwa Sistem inventaris ini telah memenuhi aspek usability.

3. Instrument Performance

Hasil pengujian performance efficiency menggunakan aplikasi online GTmetrics yang menampilkan skor hasil page speed, Y Slow, dan time load. Hasil skor rata- rata pages peed untuk semua halaman sistem informasi menunjukkan angka $86,50 \%$ dengan grade A. Skor $Y$ Slow menunjukkan angka $74,21 \%$ dengan grade C . Sedangkan rata-rata waktu load halaman 3,16 detik. Standar waktu load halaman berdasarkan ketahanan user maksimal adalah 10 detik. Sehingga dapat disimpulkan dari hasil pengujian dengan aplikasi tersebut sistem informasi Inventaris Barang telah memenuhi aspek performance efficiency.

4. Instrument Maintainability

Pengujian aspek maintainability dilakukan secara operasional dengan mengukur matriks menggunakan instrumen Land. Hasil pengujian menunjukkan sistem memenuhi tiga kriteria yaitu instrumentation, consistency, dan simplicity sehingga sistem informasi ini dapat dikatakan memenuhi aspek maintainability.

\section{Kesimpulan}


Berdasarkan hasil penelitian dari pembahasan yang telah dilakukan, dapat disimpulkan bahwa:

1) Pengembangan sistem informasi manajemen asset ini bertujuan untuk mengelola inventaris di Universitas Yudharta Pasuruan. Sistem informasi multiplatform ini memiliki dua actor utama yakni admin dan pengguna. Fitur-fitur yang dimiliki yakni mengelola data barang seperti pencarian, menambah, mengedit, menghapus dan mencetak data kedalam bentuk pdf dan excel.

2) Sistem informasi manajemen asset ini disusun pada dua platform yakni website dan android

3) Sistem informasi manajemen aset yang dikembangkan ini telah melakukan pengujian kualitas perangkat lunak yang sudah layak untuk digunakan

4) Hasil Skor dari Kuisioner Usability adalah 72, jika skor lebih dari 68 maka hasil tersebut bisa dikatakan layak untuk pengembangan aplikasi

\section{References}

[1] Al Fatta, Hanif. (2009). Analisis dan Perancangan Sistem Informasi Untuk Keunggulan bersaing Perusahaan dan Organisasi Modern. Yogyakarta: andi.

[2] A. Gima Sugiama (2013), Manajemen Aset Pariwisata Bandung: Guardaya Intimarta

[3] Hamzah, M. L., \& Purwati, A. A. (2018). Sistem Manajemen Inventori Komputer Menggunakan Near Field Communication Berbasis Android Studi Kasus di STIE Pelita Indonesia Pekanbaru. Journal of Economic, Bussines and Accounting (COSTING), 1(1), 95-104. https://doi.org/10.31539/costing.v1i1.46

[4] Nastiti, M., \& Sunyoto, A. (2012). Perancangan Aplikasi Manajemen Keuangan Pribadi Berbasis Android. Jurnal Dasi, 13(2), 38-43.

[5] Suputra, P. H., Yota, K., Aryanto, E., \& Kertiasih, N. K. (2016). Sistem Inventaris Undiksha Berbasis Mobile Dan. 280-288.

[6] Teknologi, F., Universitas, I., \& Malang, M. (2018). Desain sistem informasi inventaris berbasis web pada fakultas teknologi informasi universitas merdeka malang. 1220-1228. 